\title{
Enfrentando a violência: a percepção de profissionais da educação sobre a violação dos direitos de crianças e adolescentes
}

\author{
Aline Cardoso Siqueira* \\ Cássia Ferrazza Alves** \\ Flavia Elso Leão***
}

\section{Resumo}

As situações de violação dos direitos da criança e do adolescente são alvo de discussão de uma sociedade protetiva. É com frequência que os professores expõem suas preocupações quanto a questões que violam os direitos das crianças e adolescentes, como a violência física, sexual, psicológica e negligência que são detectadas no contexto escolar. Assim, este estudo objetivou compreender a percepção dos professores em relação à violação dos direitos das crianças e dos adolescentes. Participaram dessa pesquisa 20 professores da rede pública de Santa Maria (RS). Foram utilizados uma entrevista semiestruturada e um questionário biossociodemográfico e laboral. Entre os resultados, a violência física foi a violação mais identificada, e as formas de enfrentamento mencionadas foram acionar o Conselho Tutelar e chamar os responsáveis pela criança. A maioria dos professores apresentou-se engajada no problema, contudo, sentia-se despreparada e insegura para agir perante as situações de violação vivenciadas na escola. Dessa forma, sugere-se a construção de programas de capacitação de professores, fortalecendo-os no enfrentamento da violação dos direitos da criança e do adolescente.

Palavras-chave: professores, violação dos direitos da criança e do adolescente, escolas.

\section{Facing the violence: the perception of the education professionals about the violation of children's and adolescents' rights}

\section{Abstract}

The violation of children's and adolescents' rights is goal of concern in a protective society. We have often seen them show their concerns about the issues that violate the children's and adolescents' rights such as physical, sexual and psychological violence; negligence which is present in the school context. Thus, this study aimed at understanding the perception of teachers regarding the

\footnotetext{
* Professora Doutora do Departamento de Psicologia da Universidade Federal de Santa Maria (UFSM), Santa Maria, Rio Grande do Sul, Brasil.

** Psicóloga pelo Centro Universitário Franciscano e mestranda no Programa de Pós-Graduação em Psicologia (PPGP) da Universidade Federal do Rio Grande do Sul (UFRGS).

*** Psicóloga pelo Centro Universitário Franciscano e especializanda em "Família Contemporânea" pela Unifra. Santa Maria, Rio Grande do Sul, Brasil.
} 


\section{Aline Cardoso Siqueira - Cássia Ferrazza Alves - Flavia Elso Leão}

children's and adolescents' right violation. Twenty teachers from public schools of Santa Maria/RS participated of this study. A semi-structured interview and a biosocial-demographic and labor questionnaire were utilized. Among the results, the physical violence was the most identified violation and the ways of facing mentioned were to trigger the Tutelary Council and call the people responsible for the child. Most of the teachers were engaged to the issue; yet, they have felt unprepared and insecure for acting before violation situations experienced at school. This way, it is suggested the construction of teacher training programs which empowers them facing the violation of child's and adolescent's rights.

Keywords: teachers, violation of child's and adolescent's rights, schools.

A violação dos direitos da criança e do adolescente constitui-se em uma questão de grande relevância social, sendo evidente em todos os contextos de interação do indivíduo como, por exemplo, família, escola, unidades básicas de saúde, enfim, em ambientes públicos e privados. Por ser um fenômeno presente na sociedade, esta problemática acaba por evidenciar-se na prática dos profissionais da educação, demandando um manejo e encaminhamento dos mesmos. A atenção a estes casos não é facultativa segundo a legislação brasileira. De acordo com o Estatuto da Criança e do Adolescente (ECA, BRASIL, 1990), os profissionais da saúde e educação devem realizar uma notificação às autoridades de proteção da infância e juventude nos casos em que haja suspeita ou confirmação de maus-tratos contra crianças e adolescentes (Art. 245, BRASIL, 1990). Assim, torna-se imperativo conhecer como este processo ocorre no cotidiano das escolas.

A escola e a família são entendidas como redes fundamentais de formação de socialização e identidade da criança (FALEIROS, 1998). Porém, quando a família, lugar de proteção da criança e do adolescente, torna-se falha e omissa em efetivar essa função, a escola passa a ser instrumento fundamental, visto que o ambiente escolar acaba constituindo-se como o segundo local de vivência e socialização além da família e, por conseguinte, lugar de proteção à vítima (INOUE; RISTUM, 2008). A escola não deve assumir uma responsabilidade que é da família. Contudo, ela pode auxiliar a família no desempenho de suas funções, a partir de esclarecimentos, orientações e, quando necessário, encaminhamento a órgãos competentes (INOUE; RISTUM, 2008).

Dessa forma, torna-se importante conhecer como os educadores estão identificando e enfrentando a suspeita da violação dos direitos da criança e do adolescente, especialmente nos casos de violência, compreendendo o papel que a escola tem assumido no enfrentamento dessa problemática. É de suma importância o conhecimento desses fatores, visto que o não enfrentamento das violações dos direitos das crianças e adolescentes por parte dos profissionais da educação pode agravar a situação vivenciada pelas vítimas. 


\section{Violência contra crianças e adolescentes e o contexto escolar}

O uso de violência para o disciplinamento de crianças e adolescentes tem sido uma prática aceita pela sociedade ao longo dos tempos. A ideia de que os filhos são propriedade dos pais está fortemente enraizada na cultura cristã (ARIÈS, 1981; JAEGER; STREY, 2011). Esta concepção ainda hoje autoriza as famílias a fazer o que quiserem com seus filhos. Além disso, a instituição escolar, no passado, corroborou estas concepções e práticas. O historiador francês Ariès (1981), ao estudar a história social da criança e da família, encontrou o surgimento e a consolidação da ideia de disciplinamento das crianças no contexto escolar a partir do século XV, sendo as almas das crianças de responsabilidade dos educadores. $O$ castigo corporal e a humilhação passaram a ser usados pelos educadores com base na fraqueza da infância. Segundo Ariès (1981), o relaxamento da disciplina escolar ocorreu a partir de uma nova orientação do sentimento de infância não mais ligado à fraqueza, mas sim à ideia de que deve ser protegida e cuidada pelo adulto. A violência no âmbito escolar passou de um instrumento de disciplinamento disponível para ser hoje considerada uma grave violação dos direitos da criança e do adolescente e um problema de saúde pública (GOMES; PEREIRA, 2009; MIDLARSKY; KLAIN, 2005; ROYER, 2002; SILVA; CASTRO, 2005). Embora o fenômeno da violência não seja problema exclusivo de determinadas famílias e da sociedade, estudos indicam que o desemprego, a baixa escolaridade, vivência de violência dos pais em suas infâncias, como também eventos estressores vividos na família podem contribuir para o aumento da ocorrência da violência contra crianças e adolescentes (ABRAMOVAY, 2003; AZEVEDO; GUERRA, 2002). Assim, a violência transformou-se, ao longo do tempo, em uma problemática mais ampla, relacionada à exclusão social.

Sendo uma das vias de violação dos direitos da criança e do adolescente, a violência doméstica pode se manifestar de várias formas e com diferentes graus de severidade. A violência intrafamiliar é entendida como toda ação ou omissão que prejudique a integridade física, psicológica, bem-estar ou a liberdade de outro membro da família (BRASIL, 2002). Pode ser cometida pelos membros da família ou uma pessoa próxima e de confiança da vítima. A Pesquisa Nacional de Saúde do Escolar, realizada por Malta e colaboradores(2010), aponta que $9,5 \%$ dos estudantes entrevistados apresentavam sinais de violência intrafamiliar independentemente do sexo ou do tipo de escola (pública ou particular). O estudo foi realizado com escolares do $9^{\circ}$ ano do Ensino Fundamental de escolas públicas e privadas das capitais dos Estados brasileiros e do Distrito Federal, totalizando 60.973 participantes. Diante disso, a violência doméstica distinguise da violência intrafamiliar, já que inclui como agressores outros membros como empregados, pessoas de convivência esporádica e agregados. A violência intrafamiliar é expressa por meio da dinâmica de poder/afeto, isto é, relações de subordinação e dominação, estando os sujeitos em posições opostas, com sua dinâmica própria (BRASIL, 2002). 


\title{
Aline Cardoso Siqueira - Cássia Ferrazza Alves - Flavia Elso Leão
}

A violência manifesta-se por meio da violência física, sexual, psicológica e a negligência. A violência física constitui-se em algum dano por meio da força física ou algum tipo de arma por parte de uma pessoa que está em relação de poder com outra. Evidencia-se por meio de tapas, queimaduras, empurrões, socos, cortes, lesões por armas ou objetos, ato de obrigar o uso de álcool ou drogas, arrastar, amarrar, estrangular (AZEVEDO; GUERRA, 1989; BRASIL, 2002).

A violência sexual é entendida como toda ação produzida por uma pessoa em relação de poder sobre outra na qual envolve coerção, força física ou intimidação psicológica (BRASIL, 2002) que tem por finalidade estimular sexualmente as crianças ou os adolescentes ou utilizá-los para obter uma estimulação sexual (AZEVEDO; GUERRA, 1989) atingindo, na maioria, o sexo feminino (KRISTENSEN; OLIVEIRA; FLORES, 2000). O abuso sexual pode manifestarse sob diversas formas, envolvendo ou não contato físico. As práticas sexuais que não envolvem contato físico são assédio sexual, abuso sexual verbal, voyeurismo, exibicionismo e pornografia (BRASIL, 2004).

No que se refere ao abuso sexual intrafamiliar, na maioria dos casos, o autor da agressão é alguém que a criança confia e ama, que detém certo poder hierárquico, econômico (pai, mãe) ou afetivo (tios, avós, primos).

\begin{abstract}
A violência sexual doméstica frequentemente ocorre dentro de casa, no âmbito da vida privada, num ambiente em que a criança deveria, supostamente, sentir-se protegida. Como o lar é um espaço privado, a criança e o que acontece dentro de casa estão envolvidos numa atmosfera de segredo familiar e social. Nessas situações, é comum que o ocorrido seja mantido em segredo. Em parte, porque as relações de afinidade e consanguinidade entre crianças/adolescentes abusados e os agressores gera a complacência de outros membros da família. (BRASIL, 2004, p. 24)
\end{abstract}

A violência psicológica ou emocional está presente em todas as formas de violência, ocorrendo quando um adulto constantemente deprecia, humiIha, expõe e constrange a vítima (PIRES, 2000). É toda a ação ou omissão que causa ou visa a causar dano à autoestima, ao desenvolvimento da pessoa ou à identidade. Expressa-se por meio de humilhação, ridicularização, chantagem, desvalorização, manipulação afetiva, rechaço, ameaças. Os casos de violência psicológica são difíceis de serem percebidos. Esse tipo de violência constituise como dano à vítima, uma vez que sentir-se desmoralizado por aqueles os quais se espera o apoio, pode provocar dificuldades no seu processo de desenvolvimento (BRASIL, 2002).

Muitos estudos têm destacado os prejuízos que a violência intrafamiliar provoca às suas vítimas. Para Zellerhoff (1989), a maioria das vítimas encontra- 
se com aparência negligente, apresentando desenvolvimento inferior ao esperado para suas idades. Essas crianças podem apresentar agitação atípica, hiperatividade, desobediência e comportamento desafiador. Ao desenvolver comportamentos agressivos e provocativos, elas poderão ocasionar mais violência do agressor. Na adolescência, a violência pode ocasionar baixa auto-estima, baixo senso de autoeficácia e sintomas internalizantes, podendo levar a quadros psicopatológicos, como a depressão e, também, a comportamentos destrutivos e autodestrutivos, agressividade e delinquência. Entre os indicadores de violência sexual, destacados pela literatura, estão problemas físicos como lesões, hematomas, doenças sexualmente transmissíveis, dificuldade de ligação afetiva e amorosa, dificuldade de manter uma vida sexual saudável (BRASIL, 2004).

No que tange à identificação, os educadores podem perceber a violência física por meio de escoriações, hematomas, cicatrizações, contusões em partes do corpo em que habitualmente qualquer criança não sofreria quedas, acompanhados de indicadores comportamentais como medo dos responsáveis, fugas do lar, baixa autoestima. Já na violência psicológica, percebem-se problemas de saúde sem causa orgânica como, por exemplo, distúrbios de fala e sono juntamente com isolamento social, carência afetiva, regressão a comportamentos infantis, apatia, dificuldades escolares, entre outros. Da mesma forma, a negligência pode ser percebida por meio de necessidades não atendidas como higiene, alimentação, educação (evasão escolar), pouca atividade motora devido à falta de estimulação, aliada ao desenvolvimento de atividades impróprias para a idade como cuidado doméstico, isolamento social, carência afetiva, falta de concentração. Já a violência sexual pode ser percebida por meio de doenças psicossomáticas sem causa clínica aparente, doenças sexualmente transmissíveis, baixo controle esfincteriano, dor para sentar-se, juntamente com comportamentos hiperssexualizados, baixo nível de autoestima, necessidade de preocupação em agradar aos outros, entre outros sinais (BRASIL, 2004).

Outro indicativo a ser levado em consideração no contexto escolar é o comportamento agressivo do estudante, especialmente na infância (ARAÚJO, 2002). Durante esta etapa do desenvolvimento, a criança interage em contextos específicos, que são, em geral, o contexto familiar, o escolar e o da casa de parentes, como avós e tios. A criança que convive com adultos que resolvem seus problemas através de agressividade e violência nos contextos mais familiares, onde ela permanece mais tempo, irá aprender a usá-las também para resolver seus problemas no contexto escolar. Este processo desenvolvimental foi nomeado por Bandura como modelação (BANDURA, 1978). Assim, quando uma criança utiliza estas estratégias na resolução de seus problemas, pode-se suspeitar de que seus cuidadores familiares as utilizam no ambiente doméstico, gerando comportamentos desadaptativos na criança. Contudo, destaca-se que não se pode considerar que todo comportamento agressivo corresponde à violência intrafamiliar, visto que existem intensidades de violência, que vão de prá- 


\section{Aline Cardoso Siqueira - Cássia Ferrazza Alves - Flavia Elso Leão}

ticas educativas coercitivas a espancamentos. Mas, qualquer uma dessas intensidades pode gerar prejuízos às crianças envolvidas.

Entre os desafios que permeiam o conhecimento real de situações de violência, estão a subnotificação e a dificuldade que a família tem em reconhecer que há uma violação dos direitos da criança e adolescente. Além disso, Vagostello e colaboradores (2003) encontraram, em levantamento realizado junto a um Conselho Tutelar e a Vara de Infância e Juventude de São Paulo, que a proporção de denúncias de violência advindas de escolas é inexpressiva quando comparada a outras fontes como hospitais, vizinhos ou parentes das vítimas. Quanto há a notificação, o desafio é superar a concepção de não-veracidade do relato da vítima, que muitas vezes é apontado pelas autoridades como sendo um relato fruto da "fantasia" e, portanto, não passível de confiabilidade, levando a um desencorajamento para a quebra do silêncio (GABEL, 1997). Em muitos casos, quando há o relato da vítima, muitas crianças são levadas pela própria família a negar o discurso já feito diante da autoridade judicial devido à pressão do rompimento dos vínculos e mesmo por razões econômicas que implicam o afastamento do autor da família, sendo ele o provedor (FERREIRA; SCHRAMM, 2000). Assim, a escola precisa ter conhecimento sobre a dinâmica da violência contra a criança e o adolescente para que possa manejar estas situações de forma segura e satisfatória, não ignorando os sinais ou considerando-os como "problemas de foro familiar".

Estudos sobre a percepção de professores sobre a violação dos direitos da criança e do adolescente ainda são escassos na realidade brasileira. Os estudos de Elsen e colaboradores (2011), Inoue e Ristum (2008) e Martins (2007) representam os poucos que têm se dedicado em analisar a implicação da escola diante do fenômeno da violência. Elsen e colaboradores (2011) entrevistaram professores e orientadores pedagógicos do Ensino Fundamental de escolas públicas objetivando investigar as percepções relacionadas à violência doméstica contra crianças e adolescentes, compreender como os profissionais lidam com estas situações e de que forma a escola se organiza para lidar com o fenômeno. Entre os resultados, os pesquisadores encontraram que os docentes conhecem o fenômeno da violência e observam os seus indicadores no cotidiano escolar. Contudo, estes profissionais manifestaram sentimentos ambíguos associados ao desejo de não se envolver. O estudo de Inoue e Ristum (2008) apresentou dados confirmando o pouco envolvimento dos profissionais da educação na notificação dos casos de violência sexual, tendo em vista que de 2.522 ocorrências, apenas 22 eram protocolos de situações notificadas por profissionais da educação. Já Martins (2007) encontrou evidências de que, os docentes da rede pública de ensino da região metropolitana de Vitória possuíam pouco conhecimento do Sistema de Garantia de Direitos, não atentavam para a importância do contexto escolar no enfrentamento das situações de violação dos direitos da criança e do adolescente, como também não desenvolviam ações de prevenção à violência. 
A importância da família, escola e Estado é reiterada no artigo 227 da Constituição Federal, o qual define que:

É dever da família, da sociedade e do Estado assegurar à criança e ao adolescente, com absoluta prioridade, o direito à vida, à saúde, à alimentação, à educação, ao lazer, à profissionalização, à cultura, à dignidade, ao respeito, à liberdade e à convivência familiar e comunitária, além de colocá-los a salvo de toda forma de negligência, discriminação, exploração, violência, crueldade e opressão. (BRASIL, 1988, s/p)

Dessa forma, pode-se afirmar que se trata de um problema social importante para a sociedade e, sobretudo, de um problema que requer estratégias de identificação, combate, prevenção e enfrentamento. Todas as crianças e adolescentes, enquanto indivíduos em desenvolvimento, devem ter seus direitos garantidos. Saúde, educação, moradia e segurança são direitos básicos para o desenvolvimento da cidadania. Considerando a complexidade da problemática da violência intrafamiliar, bem como a importância da escola nesse processo, 0 objetivo desse estudo foi compreender a percepção de profissionais da educação quanto à violação dos direitos das crianças e dos adolescentes.

\section{Método}

A presente pequisa tem delineamento transversal, com abordagem quanti-qualitativa (CRESWELL, 2009). Participaram 20 profissionais da educação de escolas públicas da cidade de Santa Maria (RS) com prática profissional com crianças e adolescentes entre 5 a 27 anos. Foram estrevistados em quatros escolas de diferentes regiões da cidade.

A amostra foi composta por conveniência, método de amostragem considerado por Robson (1993) útil por envolver a escolha de participantes mais próximos e referir-se à realidade que se quer estudar. Ainda, é considerado uma das mais amplas e satisfatórias formas de amostragem utilizadas no mundo real (NACHMIAS; NACHMIAS, 1992; ROBSON, 1993).

Foram utilizados um questionário biossociodemográfico e laboral e um roteiro de entrevista semiestruturada sobre violação dos direitos da criança e do adolescente. O questionário continha questões referentes aos dados biossociodemográficos dos participantes como idade, nível de escolaridade, tempo de docência, entre outras informações. Já o roteiro de entrevista apresentava questões sobre os direitos das crianças e dos adolescentes, além de questões que investigavam a sua percepção sobre violação desses direitos.

Todas as considerações éticas foram contempladas nesse estudo. $O$ projeto foi submetido e aprovado pelo Comitê de Ética do Centro Universitário Franciscano (protocolo $\mathrm{n}^{\circ}$ 037.2010.3). Primeiramente, o projeto de pesquisa foi 


\section{Aline Cardoso Siqueira - Cássia Ferrazza Alves - Flavia Elso Leão}

apresentado às direções das escolas, e após apreciação e aprovação, foi assinado o Termo de Concordância da escola. A amostra foi composta por professores de quatro escolas públicas que aceitaram o convite de participar do estudo, considerando o critério de ter no mínimo cinco anos de experiência no atendimento de crianças e adolescentes. Assim, foi obtida a assinatura do Termo de Consentimento Livre e Esclarecido dos professores participantes após todos os esclarecimentos sobre os objetivos do estudo e procedimentos de pesquisa. As entrevistas foram realizadas nas dependências das escolas com duração, em média, de 50 minutos.

Os dados biossociodemográficos foram analisados de forma descritiva, através do levantamento da frequência e percentagens. A entrevista semiestruturada foi analisada a partir da proposta de Análise de Conteúdo de Bardin (1977), tendo também como base a legislação de proteção à infância e adolescência como o Estatuto da Criança e do Adolescente (BRASIL, 1990) e a Constituição Federal de 1988 (BRASIL, 1988).

\section{Resultados e discussão}

Dentre os participantes do estudo, 15 professores eram do sexo feminino e 5 do sexo masculino, com idades entre 32 e 65 anos. $O$ tempo de docência dos participantes variou de 5 a 47 anos. Cerca de 10\% dos participantes possuíam Ensino Médio completo ( $f=2$ ), e estavam cursando Ensino Superior (licenciatura em Filosofia e Pedagogia); $40 \%$ possuíam Ensino Superior completo ( $f=8) ; 40 \%$ possuíam pós-graduação lato sensu $(f=8)$ e $10 \%$ dos professores tinham realizado pós-graduação stricto sensu (mestrado) $(f=2)$. A carga horária dos professores, na escola, variou de três horas a 60 horas semanais. A Tabela 1 apresenta as situações consideradas pelos participantes do estudo como violação de direitos da criança e do adolescente.

Tabela 1 - Situações consideradas como violação dos direitos da criança e do adolescente

\begin{tabular}{|l|c|}
\hline \multicolumn{1}{|c|}{ Situações de violação } & Frequência $(F)$ \\
\hline ausência de condições dignas de vida & 16 \\
\hline violência física & 14 \\
\hline negligência & 11 \\
\hline violência psicológica & 7 \\
\hline violência sexual & 4 \\
\hline abandono dos pais & 2 \\
\hline
\end{tabular}


A situação mencionada com maior frequência foi a ausência de condições dignas de vida, ou seja, condições essenciais para o desenvolvimento de uma criança e adolescente enquanto sujeitos de direitos como, por exemplo, direito à alimentação, à moradia e ao acesso à escola. Tais dados estão evidentes na fala do participante 10, que disse "[...] se não vem à escola, tem direito para vir e os pais não trazem, dia frio não tá bem tapado, tem o direito de estar vestido. Quanto ao professor, se o aluno está doente tem que mandar o material para ele em casa, ele tem o direito de receber". Quando questionados a respeito de ter em vivenciado alguma situação na qual o professor suspeitasse da existência de violação dos direitos, dos 20 entrevistados, apenas quatro responderam negativamente. Estes dados demonstram que os docentes estão atentos às problemáticas da violação dos direitos, entendendo-a de forma mais ampla. Martins (2007) encontrou que 81 (51,92\%) professores, dos 151 entrevistados, já haviam se deparado com a suspeita ou confirmação de violação dos direitos da criança e do adolescente, especificadamente, a violência sexual. Da mesma forma, o estudo de Elsen e colaboradores. (2011) demonstrou que situações de violação de direitos fazem parte do cotidiano dos profissionais da educação, sendo recorrente em suas falas.

A situação mais frequente de violação dos direitos da criança e do adolescente vivenciada pelos professores entrevistados foi a violência física $(f=13)$, seguida por negligência $(f=8)$ e violência sexual $(f=6)$. Ausência de condições dignas de vida e violência psicológica foram citadas quatro vezes cada uma. Esses dados corroboram os de Vagostello e colaboradores. (2003), nos quais a violência física é mencionada como a forma de violência mais observada pelos educadores, uma vez que a violência física é detectada por meio de escoriações, hematomas e queimaduras, ou seja, sua manifestação é mais visível, por isso é mais notada (GOMES; FONSECA, 2005). Contudo, outros tipos de violência foram identificados, como um caso de negligência trazido pelo participante 2:

Os pais eram alcoólatras, solicitamos exames neurológicos, as crianças tinham uma defasagem muito grande e os pais nunca conseguiram [fazer nada a respeito]. Diziam que agendavam, mas não. As crianças faltavam de forma absurda, eram dois irmãos. Foi uma forma de violação por parte dos pais.

De acordo com Vagostello e colaboradores (2003), as faltas escolares constituem-se como forte indicador de negligência. Nas escolas entrevistadas, os participantes ressaltaram que a direção da escola realiza uma notificação ao Conselho Tutelar quando acontecem repetidas ausências escolares, em média, de cinco a sete faltas consecutivas por alunos do Ensino Fundamental. Elsen e colaboradores (2011) também demonstraram que os profissionais da educação detectam no cotidiano escolar que os alunos sofrem de violência doméstica a partir de sinais como a introspecção de uma criança, dificuldade de aprendiza- 


\title{
Aline Cardoso Siqueira - Cássia Ferrazza Alves - Flavia Elso Leão
}

gem, comportamento sexualizado, e apresentação recorrente de marcas e hematomas com justificativas frágeis.

No caso das estratégias de enfrentamento dos casos de violação dos direitos vivenciados, nove profissionais da educação disseram que encaminharam a órgãos responsáveis pela garantia dos direitos da criança, como, por exemplo, o Conselho Tutelar. Chamar os pais e encaminhar o caso à coordenação da escola foram ações tomadas por cinco participantes. Estratégias como realizar trabalho com a mãe e encaminhar o caso para assistência social foram ações mencionadas uma vez, ao passo que dois participantes não realizaram nenhum encaminhamento. Os trechos abaixo ilustram estes aspectos:

\begin{abstract}
Teve casos que aconteceram, uma menina de menor que se envolveu com um senhor, já estava morando com ele. Nós ficamos sabendo e passamos para a direção da escola que acionou o Conselho Tutelar. Agora está se criando uma rede, estamos discutindo e sabendo como melhor lidar. O importante é observar o que está acontecendo e conversar, criar um vínculo com a pessoa para que ela fale. (participante 6)

Então, já teve situações de padrasto que abusou sexualmente e a criança confessava e tinha comportamentos diferenciados em sala de aula e o professor, a gente trabalha muito com o professor, a questão de ter esse olhar atento, e daí o professor nos trazia e a gente, aos poucos, ia investigando a situação e encaminhando ao Conselho Tutelar, né (participante 15).
\end{abstract}

As falas demonstram a importância da direção da escola ser receptiva às percepções dos professores, pois, muitas vezes, os professores precisam ser apoiados para que uma ação de proteção seja tomada. Nesse sentido, torna-se fundamental não só capacitar os professores para perceber os indicadores de violação dos direitos como também criar espaços de escuta a todos os profissionais envolvidos no contexto escolar. Por outro lado, encaminhar para a direção pode representar desengajamento dos profissionais da educação, como demonstra a fala do participante 4: "[...] encaminha para a coordenação, e essa toma as iniciativas legais por que eu sou só a professora". Esta fala pode sugerir a existência de um sentimento de impotência ou desejo de não envolver-se à medida que a responsabilidade é transferida para a direção da escola. Azevedo e Guerra (1998), Abrapia (1992) e Elsen e colaboradores. (2011) também relataram o desejo de não envolvimento do professor com a situação ao delegar a solução para a direção/orientação pedagógica da escola, além da presença de sentimentos de ódio, incômodo e atitudes de indiferença. Este quadro foi denominado pela literatura como "reticência psicológica" (AZEVEDO; GUERRA, 1998).

Muitas vezes, os professores percebem que há algo de "anormal" quando seu aluno falta com frequência ou chega atrasado à aula constantemente 
(ELSEN et al., 2011). Para Pereira e Williams (2008), a sensibilidade e proximidade do professor com relação ao seu aluno que tem seus direitos violados demonstram que o professor busca conhecer seus alunos.

Os entrevistados demonstraram sentir-se despreparados não só para lidar com as situações de violação dos direitos como também com várias problemáticas que acontecem no contexto escolar. Estas situações geram sofrimento aos profissionais e a ideia de que a escola está deixando de cumprir sua principal função. Estes aspectos podem ser vistos nas falas dos participantes $9,6,16$ e 18, respectivamente: "a escola não recebe assistência que é divulgada na mídia, falta recursos humanos [...]",

Muitas coisas acontecem na família, e a escola não está preparada. Primeiro é necessário desenvolver um olhar para isso, discutir a temática, ter um rede de proteção, medidas mais intrusivas e obter mais estratégias.

Nós da direção recebemos esses meninos, porque algo de errado aconteceu, eles vêm aqui três vezes por semana, mas o professor tem que ficar com eles 5 horas aguentando coisas, então até onde a gente suporta isso? Ou aonde a gente podia buscar isso? Então, a escola está deixando de ter a função dela, de ensino-aprendizagem, deixando de lado, para entrar em um outro lado que não dela, de ensino-aprendizagem, deixando de lado, para entrar em um outro lado que não é mais nosso. Então, eu acho que a escola está abrindo muitos os braços, tá abraçando muita coisa que, eu me sinto que não estamos fazendo coisa que é da nossa função, da forma como deveria se feito. Então fica tudo mais ou menos, nada fica bem feito, porque é muita coisa.

Não, eu acho que o pessoal, os professores não estão preparados, vêm muitos problemas de família para a gente resolver em sala de aula e a gente não está preparada pra isso, a maioria dos professores não está preparada para lidar com essas situações. Daí tu tem que desenvolver a matéria e lidar com conflitos da sala de aula, né.

Assim, segundo os participantes, o contexto escolar carece de instrumentos efetivos e conhecimento de estratégias legais de auxílio aos alunos vítimas de violação. Na busca por atender a esta demanda, sua principal função de ensino-aprendizagem acaba por ficar em segundo plano, potencializando o sentimento de desamparo nesses profissionais. Uma vez que os profissionais da educação estão em contato direto com as crianças e adolescentes inseridos na escola e que a legislação vigente determina a notificação em casos de suspeita de violação dos direitos, é fundamental o preparo de todos os profissionais envolvidos no contexto escolar a fim de entender o que é violação dos direitos da criança e do adolescente, bem como desenvolver estratégias de identificação e 


\section{Aline Cardoso Siqueira - Cássia Ferrazza Alves - Flavia Elso Leão}

manejo das situações que visem a não revitimização da criança e do adolescente (BRASIL, 1990; INOUE; RISTUM, 2008).

\section{Considerações finais}

A sociedade é impactada pela violência que ocorre de uma forma desordenada que, muitas vezes, paraliza-se perante o enfrentamento e proteção da vítima. Este estudo quantitativo, demonstrou que, nas escolas a violação mais notada pelos professores foi a violência física, expressa em marcas visíveis como hematomas. Este dado demonstra que, talvez, eles também não estejam conseguindo visualizar as outras formas de violência, que são mais sutis, mas tão devastadoras em termos de seus efeitos e consequências. Outra violação salientada é a ausência de condições dignas de vida, ou seja, condições essenciais para o desenvolvimento de uma criança e adolescente como sujeito de direitos, como, por exemplo, a garantia de alimentação, de moradia e acesso à escola.

Percebeu-se que os professores, na maioria das vezes, apresentaram estratégias de enfrentamento em consonância com a legislação vigente, como socializar o problema com a coordenação e direção da escola, chamar os responsáveis pela criança ou adolescente e acionar o Conselho Tutelar. Mesmo assim, a percepção é de inoperância de suas ações, uma vez que se percebem despreparados para manejar estas situações. Os professores precisam dispor de uma rede de apoio, visto que tais ações mal conduzidas ou conduzidas de forma insegura não só não resolverão o problema, como poderão prejudicar ainda mais a condução do caso e a situação da vítima. Dessa forma, sugere-se a criação de espaços de estudo e aprendizagem sobre os direitos da criança e do adolescente, com a parceria dos órgãos de proteção, como o Conselho Tutelar, para que se possam conhecer os seu direitos.

Embora tenha sido a minoria, houve professores que nunca suspeitaram ou vivenciaram qualquer tipo de violação dos direitos. Este aspecto pode sugerir que estes professores não estão atentos ou dando a devida importância aos indicativos de violação dos direitos, cegando-se aos sinais. Assim, torna-se importante discutir no ambiente escolar o papel da escola e dos professores para a garantia dos direitos da criança e do adolescente. Em muitos casos, é no ambiente escolar que a criança demonstra a violência a qual está submetida, e se os professores "fingirem" não saberem identificar ou ainda, não acreditarem, eles estarão sendo coniventes com o agressor. Tal como Gomes e colaboradores. (1999), acredita-se que uma das maiores barreiras no enfrentamento da violência é a concepção social e o estigma associados às crianças e aos adolescentes, que muitas vezes são revitimizados pelos adultos que fingem não ouvi-los ou os desacreditam.

Dessa forma, é de grande relevância o preparo de todos os profissionais envolvidos no contexto escolar a fim de entender o que é violação dos 
direitos da criança e do adolescente, bem como estratégias de identificação e manejo das situações que visem a não revitimização da vítima. Este preparo pode ser alcançado por meio de cursos de capacitação na problemática da violência, que podem ser oferecidos pelas secretarias de educação em parceria com pesquisadores das universidades que se dedicam ao estudo desse fenômeno. O professor é fundamental na medida em que é ele que está em maior contato com o aluno e deve ser capaz de identificar comportamentos e indícios de violação dos direitos. Não se está responsabilizando os professores pela identificação e enfrentamento das situações de violação dos direitos da criança e do adolescente, visto que é preciso que todos na rede de atendimento devem estar atuando nessa problemática. Ao conhecer com propriedade os direitos das crianças, a escola poderá, inclusive, reivindicar a atuação dos demais órgãos responsáveis e contribuir efetivamente para a garantia dos direitos da criança e do adolescente.

\section{Referências}

ABRAMOVAY, M. Enfrentando a violência nas escolas: um informe do Brasil. In: UNESCO. Violência na escola: América Latina e Caribe. Brasília: UNESCO, 2003.

ARIÈS, P. História social da criança e da família. Rio de Janeiro: LTC, 1981.

ASSOCIAÇÃO BRASILEIRA MULTIPROFISSIONAL DE PROTEÇÃO À INFÂNCIAE À ADOLESCÊNCIA-ABRAPIA. Maus-tratos contra crianças e adolescentes: proteção e prevenção. Petrópolis: Autores \& Agentes \& Associados, 1992.

ARAÚJO, M. F. Violência e abuso sexual na família. Psicologia em Estudo, Maringá, v. 7, n. 2, p. 3-11, 2002.

ARIÈS, P. História social da criança e da família. Rio de Janeiro: LTC, 1981.

AZEVEDO, M. A.; GUERRA, V. N. (Orgs.). Crianças vitimizadas: a síndrome do pequeno poder. São Paulo: Iglu Editora, 1989.

Violência de pais contra filhos: a tragédia revisitada. São Paulo: LACRI/PSA/IPSUP, 1998.

Palmada já era. São Paulo: LACRI/PSA/IPSUP, 2002.

BANDURA, A. Social learning theory of Aggression. Journal of Communication, v. 28, n. 3, p.12-29, 1978.

BARDIN, L. Análise de Conteúdo. Lisboa: PO: Edições, 1977.

BARDIN, L. Análise de Conteúdo. Lisboa: PO: Edições, 1979.

BRASIL. Constituição da República Federativa do Brasil. Brasília: DF: Senado Federal,1988. 
Aline Cardoso Siqueira - Cássia Ferrazza Alves - Flavia Elso Leão

BRASIL. Estatuto da Criança e do Adolescente. Lei Federal 8.069/1990. Brasília: 1990.

BRASIL. Ministério da Educação. Guia escolar: métodos para identificação de sinais de abuso e exploração sexual de crianças e adolescentes. 2. ed. Brasília: Secretaria Especial dos Direitos Humanos e Ministério da Educação, 2004.

BRASIL. Ministério da Saúde. Secretaria de Políticas da Saúde. Violência intrafamiliar: orientações para a prática em serviço. Brasília: Ministério da Saúde, 2002.

CRESWELL, J. W. Research design: qualitative, quantitative and mixed methods approaches. 3. ed. Califórnia, SAGE Publications, 2009.

ELSEN, I.; PROSPERO, E. N.; SANCHES, E. N.; FLORIANO, C. J.; SGROTT, B. C. Escola: Um espaço de revelação da violência doméstica contra crianças e adolescentes. Psicologia Argumento, Curitiba, v. 29, n. 66, p. 303-314. 2011.

FALEIROS, V. P. A violência sexual contra crianças e adolescentes e a construção de indicadores: a crítica do poder, da desigualdades e do imaginário. In: LEAL, M. F. P; CÉSAR, M. A. (Orgs.). Indicadores de violência intrafamiliar e exploração sexual comercial de crianças e adolescentes. Brasília: CECRICA, 1998.

FERREIRA, A. L.; SCHRAMM, F. Implicações éticas da violência doméstica contra a criança para profissionais de saúde. Revista de Saúde Pública, São Paulo, v. 34, n. 6, p. 659-65. dez. 2000.

GABEL, M. (Org.). Crianças vítimas de abuso sexual. São Paulo: Summus, 1997.

GOMES, V. L. O.; FONSECA, A. D. Dimensões da violência contra crianças e adolescentes, apreendidas do discurso de professoras e cuidadoras. Texto e Contexo Enfermagem, Florianópolis, n. 14, 2005. Disponível em: http:// www.scielo.br/scielo.php?pid=S0104-0707200 5000500004\&script $=$ sci_abstract\&tlng=pt. Acesso em: 23 mar. 2010.

GOMES, R.; ALMEIDA, A.B.B.de; ECTEINS, I.B.; SOLTER, M.; PAIVA, S.C.S.de. A saúde e o direito da criança ameaçados pela violência. Revista Latino-americana de Enfermagem, Ribeirão Preto, v. 7, n. 3, p. 5-8, 1999.

GOMES, C.; PEREIRA, M. A formação do professor em face das violências das/ nas escolas. Cadernos de Pesquisa, v. 39, n. 136, 2009. p. 221-224.

INOUE, S. R. V.; RISTUM, M. Violência sexual: caracterização e análise de casos revelados na escola. Estudos de Psicologia, Campinas, v. 25, n. 1, 2008.

JAEGER, F.; STREY, M. Maternidade e violência em situações de opressão. In: JAEGER, F.; KRUEL, C. S.; SIQUEIRA, A. C. (Orgs.). Parentalidade e 
contemporaneidade: os desafios para a psicologia. Santa Maria: Editora UNIFRA, 2010. p. 11-31.

KRISTENSEN, C. H.; OLIVEIRA, M. S.; FLORES, R. Z. Violência contra crianças e adolescentes na grande Porto Alegre - Parte B: Pode piorar? In:AMENCAR (Org.). Violência doméstica. Brasília: UNICEF, 2000. p. 104-117.

MALTA, D. C; SOUZA, E. R. de; SILVA, M. M. A. da; ANDREAZZI, M. A. R. de; CRESPO, C.; MASCARENHAS, M. D. M.; PORTO, D. L.; FIGUEROA, A. L. G.; NETO, O. L. M.; PENNA, G. O. Vivência de violência entre escolares brasileiros: resultados da Pesquisa Nacional de Saúde do Escolar (PeNSE). Ciência e Saúde Coletiva, Rio de Janeiro, v. 15, p. 3053-3063, 2010.

MARTINS, M. I. D. Violência sexual contra criança e o adolescente: desconstruindo mitos, construindo práticas no contexto escolar. 2007. $117 \mathrm{f}$. Dissertação (Mestrado em Educação) - Universidade Federal do Espírito Santo. Espírito Santo, 2007.

MIDLARSKY, E.; KLAIN, H. A history of violence in the schools. In: DENMARK, F.; KRAUSS, H.; WESNER, R.; MIDLARSKY, E.; GIELEN, U. Violence in schools: cross-national and cross cultural perscpectives. United States of America: Springer, 2005.

NACHMIAS, C. F.; NACHMIAS, D. Research methods in the social sciences. New York: St. Martin's Press, 1992.

PEREIRA, P. C.; WILLIAMS, L. C. A. A concepção de educadores sobre violência domestica e desempenho escolar. Psicologia Escolar e Educacional, v. 12, n. 1, p. 139-152, 2008.

PIRES, J. M. Violência na infância: Aspectos clínicos. In: AMENCAR (Org.). Violência doméstica. Brasília: UNICEF, 2000. p. 61-70.

ROBSON, Colin. Real world research: A resource for social sciences and practioner-researcher. Oxford: Blackwell, 1993.

ROYER, É. A violência escolar e as políticas de formação dos professores. In: DEBARBIEUX, E.; BLAYA, C. (Orgs.). Violência nas escolas e políticas públicas. Brasília: UNESCO, 2002.

SILVA, H.; CASTRO, L. Formação docente e violência na escola. Psicologia da Educação, São Paulo, n. 26, 2005. p. 47-66.

VAGOSTELLO, L.; OLIVEIRA, A. S.; SILVA, A. M. DONOFRIO, V.; MORENO, T. C. Violência doméstica e escola: um estudo em escolas públicas de São Paulo. Padeia, Ribeirão Preto, v. 13, n. 26, 2003.

ZELLERHOFF, R. H. S. Violência física contra a criança. Estudos de Psicologia, Campinas, v. 2, n. 3, p. 62-74, 1989. 


\section{Aline Cardoso Siqueira - Cássia Ferrazza Alves - Flavia Elso Leão}

\section{Correspondência}

Aline Cardoso Siqueira - Rua Floriano Peixoto, 1750, sala 312. Centro. CEP 97015 372, Santa

Maria, Rio Grande do Sul.

E-mail: alinecsiq@gmail.com - cassiaferrazza@gmail.com - flavia.el@hotmail.com

Recebido em 29 de março de 2011

Aprovado em 20 de abril de 2012 